\title{
Is Social Security Harmful to the Environmental Quality?
}

\author{
Ching-Yang Liang ${ }^{1} \&$ Tsaur-Chin $\mathrm{Wu}^{2}$ \\ ${ }^{1}$ Department of Finance and Taxation, Takming University of Science and Technology, Taiwan \\ ${ }^{2}$ Department of Public Finance, Feng Chia University, Taiwan \\ Corresponding: Ching-Yang Liang, Department of Finance and Taxation, Takming University of Science and \\ Technology, No.56, Sec. 1, Huanshan Rd., Neihu District, Taipei City 11451, Taiwan (Republic of China). Tel: \\ 886-2-2658-5801 ext. 5274. E-mail: cyliang@takming.edu.tw
}

Received: September 6, 2013

Accepted: October 17, $2013 \quad$ Online Published: November 26, 2013

doi:10.5539/ijef.v5n12p110

URL: http://dx.doi.org/10.5539/ijef.v5n12p110

\begin{abstract}
This paper utilizes the two-period overlapping generations model developed by John and Pecchenino (1994) to examine the impacts of the social security program on environment quality. The main findings are as follows. First, a higher social security benefit leads to a lower environmental quality. Second, the competitive equilibrium is dynamically inefficient in the presence of the consumption externalities. Finally, two kinds of tax scheme, one based on differential environmental taxes and the other based on uniform environmental taxes, are designed to put the economy into the optimal allocation.
\end{abstract}

Keywords: social security, environmental quality, optimal taxation

\section{Introduction}

Increasing longevity and declining population growth rates shift the age distribution in OECD countries toward older age groups. There are two of the most important debates in the population aging. The one is to investigate the effects of population aging on the social security program. Related literature on the social security program can be summarized in Feldstein and Liebman (2002). They showed that the social security benefits are increased rapidly in the population aging. According to Roseveare et al. (1996), in 1995, the social security benefits absorbed $4.1 \%$ of GDP in the US, $6.6 \%$ in Japan, $10.6 \%$ in France, and $11.8 \%$ in Sweden. In 2030, the social security benefits will absorb $6.6 \%$ of GDP in the US, 13.4\% in Japan, $13.5 \%$ in France, and $15 \%$ in Sweden.

The other is to study the effects of population aging on environmental quality. The relationship between population aging and the environment was pioneered by Ono and Maeda (2001). They thought that if an individual expects to live longer, then she/he would be willing to engage in maintenance of the environment. In addition, lower rate of population growth would lessen the effects of environmental degradation produced by individual consumption. Focusing on those notions, they showed that whether aging is harmful to the environment depends on the curvature of utility function. Besides, Ono and Maeda (2002) further analyzed the effects of population aging on economic growth and the environment. They showed that the public annuity is a key factor in evaluating the effects of aging.

In addition to the literature on the effects of population aging on the social security program and environmental quality, the linkage between the social security program and environmental quality has recently attracted considerable attention. Felder and Nieuwkoop (2000), Wendner (2001), and Ono (2005; 2007) analyzed environmental tax-financed social security reform and showed that this reform improves environmental quality and welfare. Rangel's (2003) important paper considers the link between social security and environmental quality in the political economy. Rangel showed that social security's fate depends on the vote of the middle-aged group. Note that the middle-aged vote for social security not because they care about current retirees, but because they correctly believe that without social security, they will not be able to receive benefits in old age. As a result, social security is sustainable and generates a surplus that can sustain environmental investments. This is why social security can be good for the environment in the Rangel's framework.

Unlike Rangel (2003), the proposed model is based on the competitive equilibrium rather than the political equilibrium. Like Rangel, this study focuses on intergenerational environmental issues, but uses an overlapping generation model, in which pollution arises from consumption, to examine the effects of social security on environmental quality. This study incorporates social security into the John and Pecchenino's (1994) model to 
determine the effects of the competitive mechanism on the relationship between social security and environmental quality. This paper finds that social security is harmful to environmental quality, contrary to the result of Rangel (2003).

The intuition is as follows. Since an increase in the pension benefits of the older generation, combined with a rise in the pension contribution of the young, effectively shifts income from the young to the old generations. As the old generation's propensity to consume is higher than the young generation's propensity, this increases the average propensity to consume. Thus, an increase in pension benefits decreases environmental quality through increases in consumption. This is why social security is harmful to environmental quality in this model.

The connection between the social security program and environmental quality may be unfamiliar at first sight. However, as reported by OECD (2001), since the early 1990s, numerous countries have introduced environmentally related tax reform, where new environmentally related taxes have offset reduction in existing taxes. In many cases, the revenue from environmentally related taxes will be entirely or partly allocated to a reduction in social security contributions. Finland was the forerunner in introducing taxes on $\mathrm{CO}_{2}$ emissions in 1990. However, the revenues have been used to make cuts to labor income taxes. Belgium introduced a new tax on some energy products in 1993, with revenues allocated to a reduction in social security contributions. The United Kingdom introduced a landfill tax in 1996, with revenues allocated to a reduction in social security contributions. Italy adopted various environmentally related taxes in 1998, with revenues allocated to a reduction in social security contributions. Germany implemented an increase of mineral oil duties and electricity taxes in 1999, with revenues allocated to a reduction in pension insurance contributions. Sweden implemented an increase of taxes on diesel, heating oil, and electricity in 2001, with revenues allocated to a reduction in social security contributions and income taxes.

This paper examines the effects of the social security program on environmental quality with consumption externalities in a two-period overlapping generations model based on the work by John and Pecchenino (1994). The main findings are as follows. First, a higher social security benefit leads to a lower environmental quality. That is, the reduction of pollution and the social security program may be mutually conflicting rather than compatible objectives. Second, the competitive equilibrium is dynamically inefficient in the presence of the consumption externalities. Finally, two kinds of tax scheme, one based on differential environmental taxes and the other based on uniform environmental taxes, are designed to put the economy into the optimal allocation.

The rest of this paper is organized as follows. Section 2 sets up the model of the representative household. Section 3 considers the competitive equilibrium model. Section 4 presents social optimal allocations. Section 5 demonstrates optimal tax schemes and Section 6 concludes.

\section{The Model}

This study follows the framework of John and Pecchenino (1994), in which pollution arises from consumption, utilized the overlapping generation model developed by Samuelson (1958) and Diamond (1965).

To characterize the relation between the social security program and environmental quality, the proposed approach incorporates payroll tax rates and social security benefits into John and Pecchenino's model. Individual works in the first period of life and retires in the second. There is no altruism, meaning that if there were no uncertainty, each individual would leave a bequest of zero. Generation $t$ is the set of individuals who are born in period $t$. The population grows at rate $n$, so that if generation $t$ is of size $N_{t}$ then $N_{t+1}=(1+n) N_{t}$. In the working period, individual supplies one unit of labor inelastically and receive a disposable income $\left(1-\tau_{t}\right) w_{t}$, where $w_{t}$ and $\tau_{t}$ represent a wage rate and a payroll tax rate, respectively. Tax revenue is reserved exclusively for provision of social security program. Individual divides disposable income among consumption for the working period, $c_{t}^{1}$, saving for the retirement period, $s_{t}$, and payment for environmental maintenance, $m_{t}$ (Note 1). The individual consumption during the working period is

$$
c_{t}^{1}+s_{t}+m_{t}=\left(1-\tau_{t}\right) w_{t},
$$

In the retirement period, individual receives social security benefits, $b_{t+1}$, and the return on saving, $r_{t+1}$. The individual consumption during retirement is thus

$$
c_{t+1}^{2}=\left(1+r_{t+1}\right) s_{t}+b_{t+1},
$$

where $c_{t+1}^{2}$ is the consumption of an individual of generation $t$ during retirement (Note 2).

Environmental quality is public goods, defined as 


$$
Q_{t+1}=Q_{t}-\beta\left(N_{t} c_{t}^{1}+N_{t-1} c_{t}^{2}\right)+\delta N_{t} m_{t},
$$

where $Q_{t}\left(Q_{t+1}\right)$ is the aggregate environmental quality in period $t(t+1), \beta>0$ is a parameter of consumption externalities, $N_{t} c_{t}^{1}+N_{t-1} c_{t}^{2}$ is the aggregate consumption in period $t, \delta>0$ is a parameter presenting the technology required for environmental maintenance, and $N_{t} m_{t}$ is the aggregate environmental maintenance in period $t$. The pollution caused by individuals' consumption is straightforward. For example, driving an automobile causes $\mathrm{CO}_{2}$ emissions. In daily life, people inevitably generate waste products that damage the environment, regardless of what treatments are available.

Dividing equation (3) by $N_{t}$, per capita environmental quality can be obtained as

$$
(1+n) q_{t+1}=q_{t}-\beta\left[c_{t}^{1}+\frac{c_{t}^{2}}{1+n}\right]+\delta m_{t},
$$

where $q_{t} \equiv Q_{t} / N_{t}$ denotes per capita environmental quality in period $t$. The individual's utility, $\boldsymbol{U}$, is derived from consumption in the working and retirement period, and per capita environmental quality in the retirement period (Note 3), where $U^{\prime}>0$ and $U^{\prime \prime}<0$. For simplification, this study assumes that the individual's utility function is a log-linear function of the form

$$
\left.U=\ln c_{t}^{1}+\ln c_{t+1}^{2}+\ln q_{t+1} . \text { (Note } 4\right)
$$

\section{Competitive Equilibrium}

Individual chooses $c_{t}^{1}, c_{t+1}^{2}, m_{t}$, and $s_{t}$ to maximize utility (5) subject to the constraints (1), (2), and (4), taking $w_{t}, \tau_{t}, b_{t+1}, c_{t}^{2}, r_{t+1}$, and $q_{t}$ as given. This means that the private optimization problem has the first order conditions

$$
\begin{gathered}
\frac{1}{c_{t}^{1}}=\left[\frac{\beta+\delta}{1+n}\right] \frac{1}{q_{t+1}}, \\
\left(1+r_{t+1}\right) \frac{1}{c_{t+1}^{2}}=\left[\frac{\delta}{1+n}\right] \frac{1}{q_{t+1}} .
\end{gathered}
$$

Equation (6) indicates that individual chooses consumption when they are young, equating the marginal rate of substitution between consumption in youth and environmental quality in old age to the marginal rate of transformation, $(\beta+\delta) /(1+n)$. At the utility maximum, a decrease in utility due to an extra dollar of falling consumption among the young is equal to an increase in utility due to the sum of the extra utility from decreasing consumption externalities, $\beta /(1+n)$, and from increasing the environmental maintenance, $\delta /(1+n)$.Equation (7) shows that individual chooses savings to equate the marginal rate of substitution between consumption in old age and environmental quality in old age to the marginal rate of transformation, $\delta /(1+n)\left(1+r_{t+1}\right)$. At the utility maximum, a decrease in utility due to an extra dollar of falling consumption in old age is equal to an increase in utility due to an increase environmental maintenance, $\delta /(1+n)\left(1+r_{t+1}\right)$ (Note 5).

The productive sector of the economy is characterized by an aggregate production function

$$
Y_{t}=F\left(K_{t}, N_{t}\right) \text {, }
$$

where $K_{t}$ is the capital stock in period $t$. Assuming that $F\left(K_{t}, N_{t}\right)$ satisfies constant returns to scale, equation (8) then can be rewritten as

$$
y_{t}=f\left(k_{t}\right) .
$$

The production function is neoclassical: $f\left(k_{t}\right)$ with $f^{\prime}>0$ and $f^{\prime \prime}<0$, where $y_{t} \equiv Y_{t} / N_{t}$ is output per labor and $k_{t} \equiv K_{t} / N_{t}$ is capital per labor. Assume that capital does not depreciate during the production process. As the labor market is competitive, profit maximization in the choice of labor by firms implies that factors used in production are compensated by their marginal products

$$
\begin{gathered}
w_{t}=f\left(k_{t}\right)-k_{t} f^{\prime}\left(k_{t}\right), \\
r_{t}=f^{\prime}\left(k_{t}\right) .
\end{gathered}
$$


The capital market clears when $N_{t} s_{t}=K_{t+1}$. It can be rewritten as

$$
s_{t}=(1+n) k_{t+1} \text {. }
$$

At equilibrium, it is necessary that consumers maximize utility, firms maximize profit and all markets clear. Another assumption is that the social security program operates on the pay-as-you-go system. Noting that benefits are only paid once an individual has retired, the government budget constraint in period $t+1$ is

$$
N_{t+1} w_{t+1} \tau_{t+1}=N_{t} b_{t+1},
$$

where the left-hand side of equation represents the aggregate payroll tax revenues collected from workers born in period $t+1$ and the right-hand side represents the aggregate benefits paid to retired persons born in period $t$. Dividing equation (13) by $N_{t}$, equation (13) reduces to

$$
w_{t+1} \tau_{t+1}=\frac{b_{t+1}}{1+n}
$$

Combining equations (1), (2), (4), (6), (7), (10), (11), (12) and (14), leads to

$$
\begin{gathered}
(1+n) q_{t+1}=q_{t}-\beta\left[\frac{1+n}{\beta+\delta} q_{t+1}+\left(1+f^{\prime}\left(k_{t}\right)\right) k_{t}+\frac{b_{t}}{1+n}\right] \\
+\delta\left[f\left(k_{t}\right)-k_{t} f^{\prime}\left(k_{t}\right)-\frac{b_{t}}{1+n}-(1+n) k_{t+1}-\frac{1+n}{\beta+\delta} q_{t+1}\right] \\
q_{t+1}=\delta k_{t+1}+\frac{\delta b_{t+1}}{(1+n)\left(1+f^{\prime}\left(k_{t+1}\right)\right)} .
\end{gathered}
$$

\subsection{The Steady State}

Since all nominal variables and per-capita variables are constant in the steady state, time subscripts are eliminated. Let $\bar{k}$ and $\bar{q}$ denote steady state values. Equations (15) and (16) can be rewritten as

$$
\begin{gathered}
(1+2 n) \bar{q}+(\beta+\delta) \bar{k} f^{\prime}(\bar{k})-\delta f(\bar{k})+(\beta+(1+n) \delta) \bar{k}=-\frac{\beta+\delta}{1+n} b, \\
\bar{q}=\delta \bar{k}+\frac{\delta b}{(1+n)\left(1+f^{\prime}(\bar{k})\right)} .
\end{gathered}
$$

The following proposition characterizes the comparative static behavior of the steady state of this model.

Proposition 1: Under the stable condition, economies with higher social security benefits have lower capital accumulation and lower environmental quality.

Proof: Please see Appendix.

The result of this paper differs from those of Rangel (2003). This is possible because Rangel studied the effects of social security on environmental quality in the political economy. However, the proposed model is based on competitive equilibrium. The main mechanism in the present paper is as follows. An increase in the pension benefits of the older generation, combined with a rise in the pension contribution rate of the young, effectively shifts income from the young to the old generations. As the old generation's propensity to consume is higher than the young generation's propensity, this increases the average propensity to consume. Thus, an increase in pension benefits decreases environmental quality (Note 6). On the other hand, when the average propensity to consume rises, the average propensity to save falls. Consequently, the steady state level of capital falls. This is why social security is harmful to capital accumulation and environmental quality in our model.

To the best of our knowledge, there is little empirical evidence regarding the effects of social security on environmental quality in a competitive equilibrium model. However, Wilcox (1989) used data from the Social Security Bulletin in the United State during 1965-1985 and found that increases in social security have caused large increases in consumer lifetime spending. Based on Wilcox's finding, social security may affect environmental quality through consumption impacts in reality. A policy implication from this finding is that social security is not necessarily good for the environment, but depends on the particular equilibrium structure.

\section{Social Optimal Allocation}

Suppose that the social planner is an infinitely-lived government who treats all generations symmetrically. The infinitely-lived government chooses the steady-state consumption, capital stock and the environmental maintenance to maximize the utility of a representative generation. That is, the planner solves 


$$
\max _{\left\{c^{1}, c^{2}, m, k\right\}} u=\ln c^{1}+\ln c^{2}+\ln q
$$

Subject to

$$
\begin{gathered}
f(k)+k=c^{1}+\frac{c^{2}}{1+n}+(1+n) k+m, \\
q=-\frac{\beta}{n}\left[c^{1}+\frac{c^{2}}{1+n}\right]+\frac{\delta}{n} m,
\end{gathered}
$$

where equation (19) represents economic feasibility, it can be obtained by combining equation (1), (2), (10), (11) and (12) in the steady state. Equation (20) is steady-state environmental quality. Let $\widetilde{k}, \widetilde{q}, \widetilde{c}^{1}$, and $\widetilde{c}^{2}$ denote steady state values. The first-order conditions are

$$
\begin{gathered}
\frac{1}{\widetilde{c}^{1}}=\left[\frac{\beta+\delta}{n}\right] \frac{1}{\widetilde{q}}, \\
\frac{1}{\widetilde{c}^{2}}=\left[\frac{\beta+\delta}{n(1+n)}\right] \frac{1}{\widetilde{q}}, \\
f^{\prime}(\tilde{k})-n=0
\end{gathered}
$$

The economic meanings of equation (21) and (22) are similar to (6) and (7). Equation (23) means that the optimal $k$ should be chosen such that $f^{\prime}(\widetilde{k})=n$. Comparing equation (6) and (7) in the steady state with (21) and (22), this paper derives the following proposition.

Proposition 2: It is shown that the competitive equilibrium is dynamically inefficient in this economy.

The difference between equation (7) and (22) is that the retired person ignores the negative effect of consumption on environmental quality, $\beta$, in a competitive equilibrium. The reason is that the retired person does not suffer from the degraded environment, since she/he does not survive in the next period. Thus, the competitive equilibrium is dynamically inefficient in this economy.

\section{Optimal Tax Schemes}

It can be found that the competitive equilibrium is dynamically inefficient in this model in which the social security program is introduced. This section analyzes how to implements tax schemes in order to achieve efficient allocations for this economy. That is to say, this paper finds the optimal tax schemes to place stationary competitive economy in the golden rule allocation. This section will explicitly implement two kinds of tax scheme in turn. The one is introduced differential environmental taxes on consumption to finance the social security program. The other is introduced uniform environmental taxes on consumption and capital gain taxes to finance the social security program.

It is not unusual to introduce environmentally related taxes on consumption. For example, OECD (2001) revealed that 25 OECD member countries applied taxes on unleaded petrol, diesel and light fuel oil used for heating purposes. Austria, Belgium, Demark, Finland, Germany, Italy, Japan, Norway, and Sweden applied taxes on electricity consumption. Almost all OECD member countries levied some kind of tax on the sale or use of motor vehicles. Austria, Czech Republic, Denmark, Finland, Norway, Sweden, and United Kingdom introduced taxes related to the final treatment of waste. Belgium, Denmark, Finland, and Norway introduced taxes on beverage containers to reduce packaging use and packaging waste.

\subsection{Payroll Taxes Cum Differential Environmental Taxes}

The first tax scheme introduces a payroll tax and differential environmental taxes to finance the social security program, where $\dot{\tau}_{t}$ is a payroll tax rate, $\zeta_{t}^{1}$ is an environmental tax rate imposed in the working period, and $\zeta_{t+1}^{2}$ is an environmental tax rate imposed in the retirement period. Under the tax scheme, the individual problem of generation $t$ is

$$
\underset{\left\{c_{t}^{1}, c_{t+1}^{2}, m_{t}, s_{t}\right\}}{\operatorname{Max}} u=\ln c_{t}^{1}+\ln c_{t+1}^{2}+\ln q_{t+1}
$$

Subject to

$$
\left(1+\zeta_{t}^{1}\right) c_{t}^{1}+s_{t}+m_{t}=\left(1-\dot{\tau}_{t}\right) w_{t},
$$




$$
\begin{gathered}
\left(1+\zeta_{t+1}^{2}\right) c_{t+1}^{2}=\left(1+r_{t+1}\right) s_{t}+\dot{b}_{t+1}, \\
(1+n) q_{t+1}=q_{t}-\beta\left[c_{t}^{1}+\frac{c_{t}^{2}}{1+n}\right]+\delta m_{t} .
\end{gathered}
$$

Given $w_{t}, \dot{\tau}_{t}, \dot{b}_{t+1}, c_{t}^{2}, r_{t+1}$ and $q_{t}$, individual chooses $c_{t}^{1}, c_{t+1}^{2}, m_{t}$ and $s_{t}$ to maximize utility (24) subject to the budget constraints (25-1), (25-2) and the per capita environmental quality (25-3). The first-order conditions in a steady state can be obtained as

$$
\begin{gathered}
\frac{1}{c^{1}}=\left[\frac{\beta+\left(1+\zeta^{1}\right) \delta}{1+n}\right] \frac{1}{q}, \\
(1+r) \frac{1}{c^{2}}=\left[\frac{\left(1+\zeta^{2}\right) \delta}{1+n}\right] \frac{1}{q} .
\end{gathered}
$$

From the social viewpoint, the government can compare equation (21) and (22) with (26) and (27) and specify

$$
\begin{gathered}
\zeta^{1}=\frac{\beta+\delta}{\delta n}, \\
\zeta^{2}=\frac{\delta+(1+n) \beta}{\delta n} .
\end{gathered}
$$

Employing equation (10), (12), (25-1) and (28), payroll tax rate can be derived as

$$
\dot{\tau}=\frac{1}{f(\widetilde{k})-n \widetilde{k}}\left[f(\widetilde{k})-n \tilde{k}-\tilde{m}-(1+n) \tilde{k}-\frac{\beta+(1+n) \delta}{\delta n} \widetilde{c}^{1}\right] .
$$

Assume that the government budget is financed from payroll tax revenues and environmental tax revenues. Social security benefits can be obtained as

$$
\dot{b}=(1+n)(f(\widetilde{k})-n \tilde{k}) \dot{\tau}+(1+n) \widetilde{c}^{1} \zeta^{1}+\widetilde{c}^{2} \zeta^{2} .
$$

Thus, this paper derives the following proposition.

Proposition 3: Dynamically inefficient economies can achieve the optimal allocation by the following combination of payroll taxes and environmental taxes.

$$
\begin{gathered}
\zeta^{1}=\frac{\beta+\delta}{\delta n}, \zeta^{2}=\frac{\delta+(1+n) \beta}{\delta n} \\
\dot{\tau}=\frac{1}{f(\widetilde{k})-n \widetilde{k}}\left[f(\widetilde{k})-n \widetilde{k}-\tilde{m}-(1+n) \tilde{k}-\frac{\beta+(1+n) \delta}{\delta n} \widetilde{c}^{1}\right] .
\end{gathered}
$$

It is worth to note that the environmental tax of the old is higher than that of the young. This is because a person lives for two periods. When they are old, they do not take care of the negative effect of the consumption level on the environment. Thus, the government must levy the higher environmental taxes on the old (Note 7).

\subsection{Payroll Taxes Cum Uniform Environmental Taxes and Capital Gain Taxes}

The second tax scheme introduces a payroll tax, uniform environmental taxes and capital gain taxes to finance the social security program, where $\ddot{\tau}_{t}$ is a payroll tax rate imposed in the working period, $\xi^{c}$ is a uniform environmental tax rate imposed in both periods and $v$ is a capital gain tax rate imposed in the retirement period. Under the tax scheme, the individual's problem of generation $t$ is

$$
\underset{\left\{c_{t}^{1}, c_{t+1}^{2}, m_{t}, s_{t}\right\}}{\operatorname{Max}} u=\ln c_{t}^{1}+\ln c_{t+1}^{2}+\ln q_{t+1}
$$

Subject to

$$
\begin{gathered}
\left(1+\xi^{c}\right) c_{t}^{1}+s_{t}+m_{t}=\left(1-\ddot{\tau}_{t}\right) w_{t}, \\
\left(1+\xi^{c}\right) c_{t+1}^{2}=\left(1+(1-v) r_{t+1}\right) s_{t}+\ddot{b}_{t+1}, \\
(1+n) q_{t+1}=q_{t}-\beta\left[c_{t}^{1}+\frac{c_{t}^{2}}{1+n}\right]+\delta m_{t} .
\end{gathered}
$$


Given $w_{t}, \ddot{\tau}_{t}, \ddot{b}_{t+1}, v, c_{t}^{2}, r_{t+1}$ and $q_{t}$, individual chooses $c_{t}^{1}, c_{t+1}^{2}, m_{t}$ and $s_{t}$ to maximize utility (24) subject to the budget constraints (30-1), (30-2) and the per capita environmental quality (30-3). The first-order conditions in a steady state can be obtained as

$$
\begin{gathered}
\frac{1}{c^{1}}=\left[\frac{\beta+\left(1+\xi^{c}\right) \delta}{1+n}\right] \frac{1}{q}, \\
\frac{1}{c^{2}}=\left[\frac{\left(1+\xi^{c}\right) \delta}{(1+n)[1+(1+v) r]}\right] \frac{1}{q} .
\end{gathered}
$$

From the social viewpoint, the government can compare equation (21) and (22) with (31) and (32) and specify

$$
\begin{gathered}
\xi^{c}=\frac{\beta+\delta}{\delta n}, \\
v=\frac{\beta}{\beta+\delta} .
\end{gathered}
$$

Employing equation (10), (12), (30-1) and (33), payroll tax rate can be derived as

$$
\ddot{\tau}=\frac{1}{f(\widetilde{k})-n \widetilde{k}}\left[f(\widetilde{k})-n \widetilde{k}-\widetilde{m}-(1+n) \widetilde{k}-\frac{\beta+(1+n) \delta}{\delta n} \widetilde{c}^{1}\right] .
$$

Assume that the government budget is financed from payroll tax revenues, environmental tax revenues and interest income tax revenues. Social security benefits can be obtained as

$$
\ddot{b}=(1+n)(f(\widetilde{k})-n \widetilde{k}) \dot{t}+(1+n) \widetilde{c}^{1} \xi^{c}+\widetilde{c}^{2} \xi^{c}+r \widetilde{s} v .
$$

Thus, this paper derives the following proposition.

Proposition 4: Dynamically inefficient economies can achieve the optimal allocation by the following combination of payroll taxes, uniform environmental taxes and capital gain taxes.

$$
\begin{gathered}
\xi^{c}=\frac{\beta+\delta}{\delta n}, v=\frac{\beta}{\beta+\delta}, \\
\ddot{\tau}=\frac{1}{f(\widetilde{k})-n \widetilde{k}}\left[f(\widetilde{k})-n \widetilde{k}-\tilde{m}-(1+n) \tilde{k}-\frac{\beta+(1+n) \delta}{\delta n} \widetilde{c}^{1}\right] .
\end{gathered}
$$

Compare equation (33) with (28) and (29), it can be found that $\xi^{c}=\zeta^{1}$ and $\xi^{c}<\zeta^{2}$. That is, the consumption level of the old is higher than the optimal. Thus, the government can achieve the optimal consumption level by imposing additionally capital gain taxes on the old. It is worth noting that if $n<2$, then $v<\xi^{c}$. This implies that the environmental tax rate levied by the government is a direct way to reduce consumption externalities, whereas the capital gain tax rate is an indirect way. Thus, the environmental tax rate is higher than capital gain tax rates on the old.

\section{Conclusion}

This paper provides a theoretical analysis of the relationship between the social security program and environmental quality, and discusses how to design tax schemes in order to put the economy into efficient allocations. It is shown that a higher social security benefit leads to a lower environmental quality. This result tends to reflect that the social security program will increase consumption and thus environmental degradation. This has a policy implication for the conflict between the social security program and environmental quality. On the other hand, it is demonstrated that the competitive equilibrium is dynamically inefficient in the presence of the consumption externality. Thus, it is shown how to design two tax schemes, one based on differential environmental taxes and the other based on uniform environmental taxes, to put the economy into the optimal allocation.

\section{References}

Diamond, P. A. (1965). National debt in a neoclassical growth model. American Economic Review, 55, 11261150.

Felder, S., \& Nieuwkoop, R. V. (2000). Using revenue from an energy tax to finance social security: A dynamic general equilibrium model for Switzerland. International Journal of Sustainable Development, 3, 136-145. http://dx.doi.org/10.1504/IJSD.2000.001528 
Feldstein, M., \& Liebman, J. B. (2002). Social security. In A. J. Auerbach, \& M. Feldstein (Eds.), Handbook of public economics (Vol. 4, pp. 2245-2324). Amsterdam: Elsevier Science.

John, A., \& Pecchenino, R. (1994). An overlapping generations model of growth and the environment. Economic Journal, 104, 1393-1410. http://dx.doi.org/10.2307/2235455

John, A., Pecchenino, R., Schimmelpfennig, D., \& Schreft, S. (1995). Short-lived agents and the long-lived environment. Journal of Public Economics, 58, 127-141. http://dx.doi.org/10.1016/0047-2727

OECD. (2001). Environmentally related taxes in OECD countries: Issues and strategies. Paris and Washington, DC.

Ono, T. (1996). Optimal tax schemes and the environmental externality. Economics Letters, 53, 283-289. http://dx.doi.org/10.1016/S0165-1765(96)00931-7

Ono, T. (2002). The effects of emission permits on growth and the environment. Environmental and Resource Economics, 21, 75-87.

Ono, T. (2005). Environmental-tax-financed social security tax cuts and the double dividend. Finanz Archiv, 61, 178-200. http://dx.doi.org/10.1628/0015221054553548

Ono, T. (2007). Growth and welfare effects on an environmental tax-based public pension reform. Japanese Economic Review, 58, 362-381. http://dx.doi.org/10.1111/j.1468-5876.2007.00361.x

Ono, T., \& Maeda, Y. (2001). Is aging harmful to the environment? Environmental and Resource Economics, 20 , $113-127$.

Ono, T., \& Maeda, Y. (2002). Sustainable development in an aging economy. Environment and Development Economics, 7, 9-22. http://dx.doi.org/10.1017/S1355770X02000025

Pecchenino, R., \& Pollard, P. S. (1997). The effects of annuities, bequests, and aging in an overlapping generations model of endogenous growth. Economic Journal, 107, 26-46. http://dx.doi.org/10.1111/1468-0297.00140

Rangel, A. (2003). Forward and backward intergenerational goods: Why is social security good for the environment. American Economic Review, 93, 813-834. http://dx.doi.org/10.1257/000282803322157106

Roseveare, D., Leibfritz, W., Fore, D., \& Wurzel, E. (1996). Ageing population, pension systems and government budgets: Simulations from 20 countries. Economics Department Working Paper, 168. Paris: OECD. http://dx.doi.org/10.1787/463240307711

Samuelson, P. (1958). An exact consumption-loan model of interest with or without the social contrivance of money. Journal of Political Economy, 66, 467-482. http://dx.doi.org/10.1086/258100

Wendner, R. (2001). An applied dynamic general equilibrium model of environmental tax reforms and pension policy. Journal of Policy Modeling, 23, 25-50. http://dx.doi.org/10.1016/S0161-8938(00)00025-9

Wilcox, D. W. (1989). Social security benefits, consumption expenditure, and the life cycle hypothesis. The Journal of Political Economy, 97, 288-304. http://dx.doi.org/10.1086/261604

\section{Notes}

Note 1 . The superscript ' 1 ' denotes when an individual is young. The subscript ' $t$ ' means period $t$.

Note 2. The superscript ' 2 ' denotes when an individual is old. The subscript ' $t+1$ ' means period $t+1$.

Note 3. Aggregate environmental quality grows at rate $n$ because of the specification of our model. If an individual obtains utility form aggregate environmental quality, then utility will increase over time. To permit a steady-state analysis, this study assumes that environmental quality is defined in per capita form.

Note 4. This formulation can be viewed in John et al. (1995), Pecchenino and Pollard (1997), Ono and Maeda (2002), and Ono(2002).

Note 5. Following John and Pecchenino (1994, p 1397), this study preclude the possibility that individual chooses not to engage in maintenance.

Note 6. The sources of affecting environmental quality include payments for environmental maintenance, $m_{t}$. A higher payroll tax rate leads to lower environmental maintenance and thus lower environmental quality.

Note 7. This analysis parallels the approach derived by Ono (1996) who highlights the optimal tax schemes in an overlapping generations model with the environmental externality. 
Note 8. This condition can be hold if production function is a form of Cobb-Douglas function as can be seen in Pecchenino and Pollard (1997), Ono and Maeda (2002), and Ono(2002).

\section{Appendix}

First, to prove the stability of the steady-state equilibrium, equation (17) and (18) can be rewritten as

$$
\begin{gathered}
\bar{q}=\frac{1}{1+2 n}\left[-\frac{\beta+\delta}{1+n} b-(\beta+(1+n) \delta) \bar{k}+(\delta-(\delta+\beta) \rho(\bar{k})) f(\bar{k})\right] \equiv \psi(\bar{k}), \\
\bar{q}=\delta \bar{k}+\frac{\delta b}{(1+n)\left(1+f^{\prime}(\bar{k})\right)} \equiv \phi(k),
\end{gathered}
$$

where $\rho(\bar{k}) \equiv \bar{k} f^{\prime}(\bar{k}) / f(\bar{k})$. We have

$$
\begin{gathered}
\psi^{\prime}(\bar{k})=\frac{1}{1+2 n}\left[-(\beta+(1+n) \delta)-(\delta+\beta) \bar{k} f^{\prime \prime}(\bar{k})\right], \\
\phi^{\prime}(\bar{k})=\delta-\frac{b f^{\prime \prime}(\bar{k})}{(1+n)\left(1+f^{\prime}(\bar{k})\right)^{2}}>0 .
\end{gathered}
$$

Since the second order derivatives of $\psi(\bar{k})$ and $\phi(\bar{k})$ are ambiguous, the possible figure is illustrated in figure A1.1 to figure A1.4. There is a steady-state equilibrium in figure A1.1 and A1.2. When the capital stock is less than $k_{L}$, the equilibrium path converges to $k=0$. When the capital stock is larger than $k_{L}$, the equilibrium path converges to $k=k_{H}$. There is no steady-state equilibrium in figure A1.3 and A1.4. Thus, the condition of the steady-state equilibrium is satisfied by $\phi^{\prime}(\bar{k})>\psi^{\prime}(\bar{k})$.

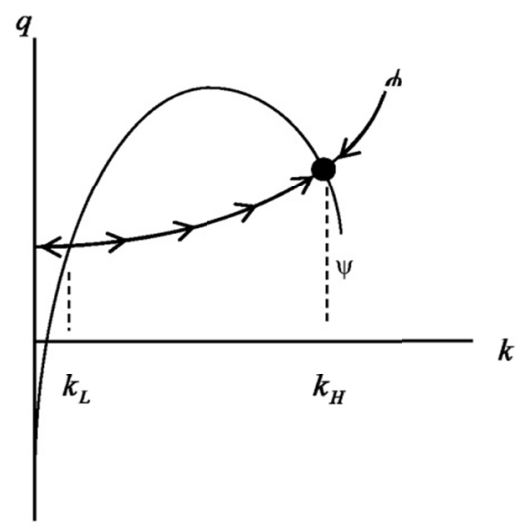

Figure A1.1

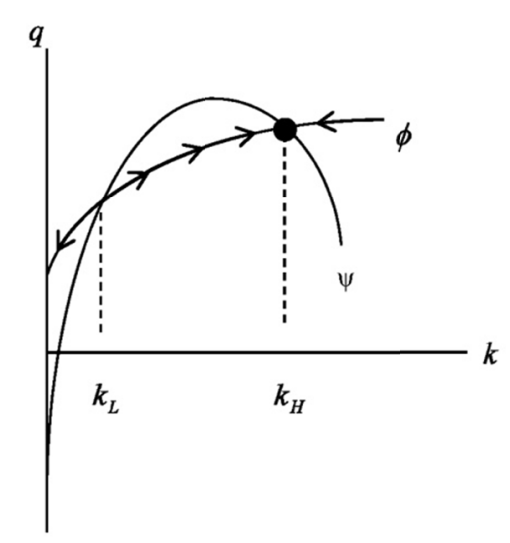

Figure A1.2 


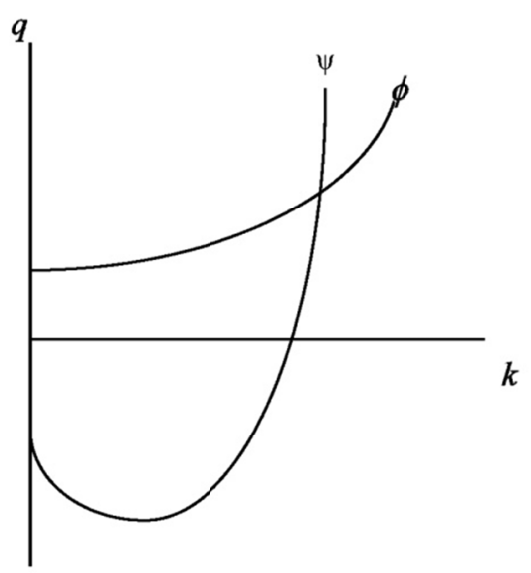

Figure A1.3

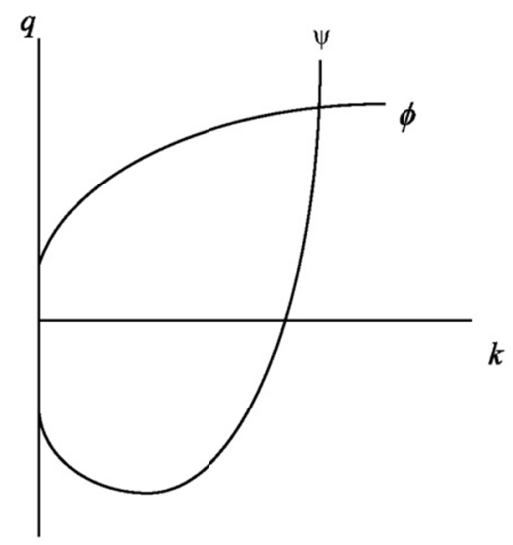

Figure A1.4

Second, totally differentiating equation (17) and (18), taking $\beta, \delta$, and $n$ as given, so that

$$
\left[\begin{array}{cc}
1+2 n & \beta f^{\prime}(\bar{k})+(\beta+\delta) \bar{k} f^{\prime \prime}(\bar{k})+\beta+(1+n) \delta \\
(1+n)\left(1+f^{\prime}(\bar{k})\right) & (1+n)(\bar{q}-\delta \bar{k}) f^{\prime \prime}(\bar{k})-(1+n)\left(1+f^{\prime}(\bar{k})\right) \delta
\end{array}\right]\left[\begin{array}{c}
d \bar{q} \\
d \bar{k}
\end{array}\right]=\left[\begin{array}{c}
-\frac{\beta+\delta}{1+n} \\
\delta
\end{array}\right] d b .
$$

The determinant of the left-hand-side matrix is

$$
\begin{aligned}
\Delta & \equiv\left|\begin{array}{cc}
1+2 n & \beta f^{\prime}(\bar{k})+(\beta+\delta) \bar{k} f^{\prime \prime}(\bar{k})+\beta+(1+n) \delta \\
(1+n)\left(1+f^{\prime}(\bar{k})\right) & (1+n)(\bar{q}-\delta \bar{k}) f^{\prime \prime}(\bar{k})-(1+n)\left(1+f^{\prime}(\bar{k})\right) \delta
\end{array}\right| \\
& =(1+n)\left\{\frac{(1+2 n) f^{\prime \prime}(\bar{k}) b \delta}{(1+n)\left(1+f^{\prime}(\bar{k})\right)}-\left(1+f^{\prime}(\bar{k})\right)\left[\left(1+f^{\prime}(\bar{k})+\bar{k} f^{\prime \prime}(\bar{k})\right) \beta+\left(2+3 n+\bar{k} f^{\prime \prime}(\bar{k}) \delta\right)\right]\right\} .
\end{aligned}
$$

Assume that $f^{\prime}(\bar{k})>n>-\bar{k} f^{\prime \prime}(\bar{k})-1$ and thus obtain $\Delta<0$ (Note 8). In the presence of the social security program, the effects of an increase in the social security benefit on capital accumulation and environmental quality can be written as 


$$
\begin{aligned}
\frac{d \bar{q}}{d b} & =\frac{1}{\Delta}\left[-(\beta+\delta) f^{\prime \prime}(\bar{k}) \bar{q}+\left(f^{\prime}(\bar{k})-n\right) \delta^{2}\right]<0, \\
\frac{d \bar{k}}{d b} & =\frac{1}{\Delta}\left[(1+2 n) \delta+(\beta+\delta)\left(1+f^{\prime}(\bar{k})\right)\right]<0 .
\end{aligned}
$$

Q.E.D.

\section{Copyrights}

Copyright for this article is retained by the author(s), with first publication rights granted to the journal.

This is an open-access article distributed under the terms and conditions of the Creative Commons Attribution license (http://creativecommons.org/licenses/by/3.0/). 